\title{
Comparative Proteomics Analysis of Human Macrophages Infected with Virulent Mycobacterium bovis
}

\begin{abstract}
Pei Li ${ }^{1,2}$, Rui Wang 1,2, Wenqi Dong ${ }^{1,2}$, Linlin Hu ${ }^{1,2}$, Bingbing Zong ${ }^{1,2}$, Yanyan Zhang ${ }^{1,2}$, Xiangru Wang ${ }^{1,2}$, Aizhen Guo ${ }^{1,2}$, Anding Zhang ${ }^{1,2}$, Yaozu Xiang ${ }^{3}$, Huanchun Chen ${ }^{1,2}$ and Chen $\operatorname{Tan}^{1,2 *}$

${ }^{1}$ State Key Laboratory of Agricultural Microbiology, College of Veterinary Medicine, Huazhong Agricultural University, Wuhan, China, ${ }^{2}$ Key Laboratory of Development of Veterinary Diagnostic Products, Ministry of Agriculture, Huazhong Agricultural University, Wuhan, China, ${ }^{3}$ Advanced Institute of Translational Medicine, School of Life Sciences and Technology, Tongji University, Shanghai, China
\end{abstract}

Mycobacterium bovis (M. bovis), the most common pathogens of tuberculosis (TB), is virulent to human and cattle, and transmission between cattle and humans warrants reconsideration concerning food safety and public health. Recently, efforts have begun to analyze cellular proteomic responses induced by Mycobacterium tuberculosis ( $M$. tb). However, the underlying mechanisms by which virulent $M$. bovis affects human hosts are not fully understood. For the present study, we utilized a global and comparative labeling strategy of isobaric tag for relative and absolute quantitation (iTRAQ) to assess proteomic changes in the human monocyte cell line (THP-1) using a vaccine strain and two virulent strains $H 37 R v$ and $M$. bovis. We measured 2,032 proteins, of which 61 were significantly differentially regulated. Ingenuity Pathway Analysis was employed to investigate the canonical pathways and functional networks involved in the infection. Several pathways, most notably the phagosome maturation pathway and TNF signaling pathway, were differentially affected by virulent strain treatment, including the key proteins CCL20 and ICAM1. Our qRT-PCR results were in accordance with those obtained from iTRAQ. The key enzyme MTHFD2, which is mainly involved in metabolism pathways, as well as LAMTOR2 might be effective upon M. bovis infection. String analysis also suggested that the vacuolar protein VPS26A interacted with TBC1D9B uniquely induced by $M$. bovis. In this study, we have first demonstrated the application of iTRAQ to compare human protein alterations induced by virulent $M$. bovis infections, thus providing a conceptual understanding of mycobacteria pathogenesis within the host as well as insight into preventing and controlling TB in human and animal hosts' transmission.

Keywords: M. tb, M. bovis, THP-1 cell, iTRAQ, proteomics, pathway analysis

\section{INTRODUCTION}

Tuberculosis (TB) is an infectious disease that greatly impacts human and animal health worldwide. TB is caused by members of the Mycobacterium tuberculosis (M. $t b$ ) complex (MTBC), of which $M$. $t b$ is a primary causative agent in humans. A recent report on global tuberculosis from the World Health Organization (WHO) indicated that 10.4 million people became ill and that 1.8 
million died from TB in 2015 (World Health Organization, 2016). In a study in which cattle were artificially infected with two M. $t b$ strains, it was confirmed that $M$. $t b$ is virulent to cattle (Chen et al., 2013). Tuberculosis in animals is primarily observed in cattle and other bovids, for which the disease is generally referred to as bovine tuberculosis (bTB) and is mainly caused by Mycobacterium bovis (M. bovis). Animal tuberculosis bears a zoonotic potential and is therefore a public health concern (Cosivi et al., 1998; Renwick et al., 2007; Michel et al., 2010; Koul et al., 2011). Thus, $M$. $t b$ and $M$. bovis are the most common pathogens within the MTBC (Ernst et al., 2007). Although $M$. bovis is the main causative agent of bTB, it has the broadest host range among all MTBC members (Meikle et al., 2011). Globally, most cases of zoonotic TB caused by $M$. bovis have been anecdotally reported, including TB in humans that is usually associated with extrapulmonary TB (Ayele et al., 2004; Müller et al., 2013; Gallivan et al., 2015; Jiang et al., 2015; El-Sayed et al., 2016). M. bovis resulted from genomic evolutionary reduction of $M$. $t b$, although the two species share 99.95\% genomic identity (Garnier et al., 2003; Bigi et al., 2016). Since 1921, M. bovis bacillus Calmette-Guérin (BCG) has been recognized as an important and available vaccine to prevent tuberculosis worldwide (Mahairas et al., 1996). It is an attenuated strain of $M$. bovis developed by Calmette and Guérin, which lost its virulence after 230 passages over a period of 13 years (Hsu et al., 2003; Seki et al., 2009). As M. bovis causes zoonotic diseases (Dye and Williams, 2010), it is necessary to have a conceptual and clear understanding of mycobacteria transmission dynamics and pathogenesis within populations and between hosts, thus providing insight into better improvement of TB control through novel and collaborative research and public health efforts.

Macrophages (MФs) are the primary effector cells responsible for killing $M$. tb through various mechanisms, including the induction of toxic anti-microbial effectors, stimulation of microbe intoxication mechanisms, apoptosis, lipid mediators, microRNAs, and cytokines (van Crevel et al., 2002; Rajaram et al., 2014; Weiss and Schaible, 2015). However, MTBC can evade host immunity to create a favorable environment for intracellular replication via their lipids, inhibition of phagosomelysosome fusion and phagosome acidification, hijacking host cell signaling, downregulation of host gene expression, and formation of granuloma (Cosma et al., 2003; Rohde et al., 2007; Davis and Ramakrishnan, 2009; Meena, 2010; Arbues et al., 2015; Chandran et al., 2015; Colonne et al., 2016). Therefore, quantitative and comparative proteomic analyses have been used to provide complementary information about host responses to MTBC infection, particularly $M$. $t b$ (Giri et al., 2010; Schmidt and Völker, 2011; He et al., 2012; Jamwal et al., 2013; Kunnath-Velayudhan and Porcelli, 2013; Petriz and Franco, 2014). Researchers have identified eight intraphagosomal expressed proteins of the BCG strain during infection with macrophages (Singhal et al., 2016). Such proteomic data have provided enhanced characterization of MTBC and host-derived targets to better improvement of TB control. While the vast majority of proteomic research about virulent $M$. bovis-host interaction focused on biomarkers during infection of cattle, MTBC natural reservoir hosts, such as the Eurasian wild boar
(Sus scrofa), and clinical specimens have also been assessed (Naranjo et al., 2007; Garton et al., 2008; Seth et al., 2009; Blanco et al., 2014; Lamont et al., 2014; Young et al., 2014; Esterhuyse et al., 2015; López et al., 2016).

M. bovis is responsible for great economic losses and cattleto-human transmission and represents a severe threat to public health (Cosivi et al., 1995; Fogel, 2015). Since the pathogenesis of bTB is not as well understood as human tuberculosis, we employed proteomic analyses by examining activated THP-1 cells infected with the vaccine strain BCG and two virulent MTBC strains, including M. $t b-H 37 R v$ and M. bovis, by isobaric tag for relative and absolute quantitation (iTRAQ). We identified and measured 2,032 proteins with two or more peptides at $>99 \%$ confidence and found that 61 were significantly regulated. There also were major differences in the proteins and pathways induced by the virulent MTBC strains when compared to the vaccine strain BCG. H37Rv and M. bovis both induced significant upregulation of several proteins in the TNF signaling pathway. Immunological disease, as well as inflammatory response and disease, were more prominent upon infection of cells with virulent $H 37 R v$ and $M$. bovis than the BCG strain. This work serves as an enhancement of the understanding that $M$. bovis affects proteins obtained from human host cells. These results may provide useful insights in understanding MTBC pathogenesis, particularly $M$. bovis, revealing novel biomarkers that may be critical to TB cattle-to-human transmission and diagnosis. Such foundational knowledge we have obtained from this study may drive more efficacious treatment and hopefully eventual eradication of TB.

\section{MATERIALS AND METHODS}

\section{Bacterial Strains and Culture Conditions}

The M. $t b$ reference strain H37Rv (ATCC 27294), BCG Tokyo strain (ATCC 35737), and M. bovis (ATCC 19210) were kindly provided by Dr. Chuanyou Li, Beijing Tuberculosis \& Thoracic Tumor Research Institute (Beijing, China). All strains were cultured to mid-log phase in Middlebrook 7H9 medium (Becton Dickinson and Company, Franklin Lakes, NJ, USA) supplemented with $10 \%$ oleic acid, albumin, dextrose, and catalase medium (OADC) (Becton Dickinson and Company) and $0.05 \%$ Tween 80 (Amresco Inc., Solon, OH, USA) with agitation. Cultures were maintained in a biosafety level 3 facility at Huazhong Agricultural University (Wuhan, China) and stored at $-80^{\circ} \mathrm{C}$. Bacteria were harvested from the culture medium by centrifugation at 4,000 g for $10 \mathrm{~min}$ washed once in 1,640 medium, resuspended in 1,640 to an OD600 of 1, equivalent to $3 \times 10^{8}$ bacteria/ml. Before measuring the absorbance at $600 \mathrm{~nm}$, a syringe connected to a sterile needle was used to scatter the bacterial clumps.

For the colony counting assay, bacteria were serially diluted 10 -fold with Middlebrook's 7H11 medium and $0.1 \mathrm{ml}$ of each dilution was transferred to $7 \mathrm{H} 11$ plates. Bacteria were grown for about 4 weeks until the colonies were suitable for counting by eye. Bacterial concentration was recorded as c.f.u. $\mathrm{ml}^{-1}$. CFUs were calculated from the actual colony counts obtained to guarantee the same initial infection dose. Detailed protocols and 
culture conditions are described elsewhere (Kumar et al., 2010; Wassermann et al., 2015).

\section{Cell Culture and Infection}

The human monocyte cell line THP-1 was cultured in RPMI 1,640 supplemented with $2 \mathrm{mM}$ L-glutamine and 10\% FBS (Hyclone, GE Healthcare Life Science, Grand Island, USA). THP1 cells were activated using $100 \mathrm{ng} / \mathrm{mL}$ phorbol myristate acetate (PMA) and incubated at $37^{\circ} \mathrm{C}$ in a $5 \% \mathrm{CO}_{2}$ atmosphere for 48 h. To reduce the effect of PMA from THP-1 cells, the medium was replaced, and incubation was continued for another $8 \mathrm{~h}$. They were then infected with $H 37 R v, M$. bovis, or BCG at an MOI of 10 (10 bacteria to one cell) (Hmama et al., 1998; Chen et al., 2013; Zhang et al., 2013; Wassermann et al., 2015). After $24 \mathrm{~h}$, cells were collected, washed three times with ice-cold phosphate-buffered saline (PBS) and processed for iTRAQ analysis or total RNA extraction. Three independent experiments were performed.

\section{Protein Preparation, Protein Digestion, and iTRAQ Labeling}

The MTBC-infected and mock-infected cells in $10 \mathrm{~cm}$ cell culture flasks were collected using cell scrapers and suspended in $400 \mu \mathrm{L}$ lysis buffer containing $8 \mathrm{M}$ urea, $30 \mathrm{mM}$ HEPES, $1 \mathrm{mM}$ PMSF, 2 mM EDTA, and $10 \mathrm{mM}$ DTT. Further lysate debris was moved by centrifugation at $20,000 \mathrm{~g}$ for $30 \mathrm{~min}$ at $4^{\circ} \mathrm{C}$ after ultrasonication treatment for $5 \mathrm{~min}$ (pulse on: $2 \mathrm{~s}$ and pulse off: $3 \mathrm{~s}$; power: 180 $\mathrm{W})$. The supernatants were reduced with $10 \mathrm{mM} \mathrm{DTT}$ at $56^{\circ} \mathrm{C}$ for $1 \mathrm{~h}$ and alkylated with $55 \mathrm{mM}$ IAM in the darkroom for 1 h. The protein mixtures were precipitated by adding $4 \times$ volume of chilled acetone at $-20^{\circ} \mathrm{C}$ overnight. After centrifugation at $20,000 \mathrm{~g}$ for $30 \mathrm{~min}$ at $4^{\circ} \mathrm{C}$, the pellet was dissolved in $0.5 \mathrm{M}$ TEAB (Applied Biosystems, Milan, Italy) with $0.1 \%$ SDS via an ultrasonication treatment for $5 \mathrm{~min}$. After centrifuging at $20,000 \mathrm{~g}$ for $30 \mathrm{~min}$ at $4^{\circ} \mathrm{C}$, an aliquot of the supernatant was taken to determine protein concentration via the Bradford assay (Sangon Biotech, Shanghai, China).

For each sample, total protein $(100 \mu \mathrm{g})$ was digested with 3.3 $\mu \mathrm{l}$ of trypsin $(1 \mu \mathrm{g} / \mu \mathrm{l})$ (Promega, Madison, WI, USA) at $37^{\circ} \mathrm{C}$ for $24 \mathrm{~h}$. After trypsin digestion, peptides were dried via vacuum centrifugation. Peptides were reconstituted in $0.5 \mathrm{M}$ TEAB and processed according to the manufacturer's instructions (Applied Biosystems). Briefly, one unit of iTRAQ reagent (AB Sciex, Foster City, CA, USA) was thawed and reconstituted in $24 \mu \mathrm{L}$ isopropanol. Samples were labeled with the iTRAQ tags as follow: BCG-infected samples (tag 115), H37R $v$-infected samples (tag 116), M. bovis-infected samples (tag 117), and mock-infected samples (tag 118). The peptides were then incubated at room temperature for $2 \mathrm{~h}$. The labeled samples were then mixed and dried with a rotary vacuum concentrator.

\section{LC-MS/MS Analysis}

Strong cation exchange (SCX) chromatography (Phenomenex, USA) was performed with an LC-20AB HPLC pump system (Shimadzu, Kyoto, Japan) to separate samples. The iTRAQlabeled peptide mixtures were reconstituted and dissolved in buffer $\mathrm{A}\left(10 \mathrm{mM} \mathrm{KH}_{2} \mathrm{PO}_{4}\right.$ in $\left.25 \% \mathrm{ACN}, \mathrm{pH} 3.0\right)$ and loaded onto a $4.6 \times 250 \mathrm{~mm}$ Ultremex SCX column containing $5 \mu \mathrm{m}$ particles (Phenomenex). The peptides were eluted at a flow rate of $1 \mathrm{~mL} / \mathrm{min}$ with a gradient of buffer A for $30 \mathrm{~min}, 5-50 \%$ buffer $\mathrm{B}\left(10 \mathrm{mM} \mathrm{KH}_{2} \mathrm{PO}_{4}\right.$ and $2 \mathrm{M} \mathrm{KCl}$ in $\left.25 \% \mathrm{ACN}, \mathrm{pH} 3.0\right)$ for $27 \mathrm{~min}$, and $60-100 \%$ buffer $\mathrm{B}$ for $15 \mathrm{~min}$. The system was then maintained at $100 \%$ buffer B for 1 min before equilibrating with buffer $\mathrm{A}$ for $10 \mathrm{~min}$ prior to the next injection. The eluted peptides were desalted with a Strata X C18 column $(100 \times 75$ mm; $5 \mu \mathrm{m}$ particles; $300 \AA$ aperture; Phenomenex, USA) and vacuum dried.

The fractions above were dissolved in aqueous solution containing $0.1 \% \mathrm{FA}$ and $2 \% \mathrm{ACN}$ and then centrifuged at $12,000 \mathrm{~g}$ for $10 \mathrm{~min}$ at $4^{\circ} \mathrm{C}$. Five micrograms supernatant was loaded on an LC-20AD nano HPLC (Shimadzu, Kyoto, Japan) by the auto sampler onto a $2 \mathrm{~cm} \mathrm{C18} \mathrm{trap} \mathrm{column} \mathrm{(inner} \mathrm{diameter} 200 \mu \mathrm{m}$, Waters), and the peptides were eluted onto a resolving $10 \mathrm{~cm}$ analytical C18 column (inner diameter $75 \mu \mathrm{m}$, Waters). The mobile phases used were composed of solvent A (0.1\% FA and $5 \% \mathrm{ACN})$ and solvent $\mathrm{B}(0.1 \% \mathrm{FA}$ and $95 \% \mathrm{ACN})$. The gradient was run at $400 \mathrm{~nL} / \mathrm{min}$ for $48 \mathrm{~min}$ at $5-80 \%$ solvent $\mathrm{B}$, followed by running a linear gradient to $80 \%$ for $7 \mathrm{~min}$, maintained at $80 \% \mathrm{~B}$ for $3 \mathrm{~min}$, and finally returned to $5 \%$ in $7 \mathrm{~min}$. The peptides were subjected to nano electrospray ionization followed by tandem mass spectrometry (MS/MS) in a Q EXACTIVE (Thermo Fisher Scientific, San Jose, CA, USA) coupled to the HPLC. Intact peptides were detected in the Orbitrap at a resolution of 70,000 and a mass range of $350-2,000 \mathrm{~m} / \mathrm{z}$. Peptides were selected for MS/MS using high-energy collision dissociation (HCD), and ion fragments were detected in the Orbitrap at a resolution of 17,500. The electrospray voltage applied was $1.8 \mathrm{kV}$. MS/MS analysis was required for the 15 most abundant precursor ions, which were above a threshold ion count of 20,000 in the MS survey scan, including a following dynamic exclusion duration of $15 \mathrm{~s}$.

\section{Bioinformatics and Data Analysis}

Raw data files acquired from the mass spectrometers were converted into MGF files using 5,600 MS converter, and the MGF files were searched. Protein identification was performed using the Mascot search engine (Matrix Science, London, UK; version 2.3.0) against the Uniprot_2015_human database (containing 20,194 sequences). For protein identification, a mass tolerance of $15 \mathrm{ppm}$ was permitted for intact peptide masses and 0.05 Da for fragmented ions, with allowance for one missed cleavage in the trypsin digests. Gln $\rightarrow$ Pyro-Glu (N-term Q), oxidation $(\mathrm{M})$, and deamidated (NQ) were potential variable modifications and carbamidomethyl (C), iTRAQ 8plex (K), iTRAQ 8plex (Y), iTRAQ 8plex (N-term) were fixed modifications. Specifically, an automatic decoy database search was performed in Mascot by choosing the decoy checkbox in which a random sequence of the database is generated and tested for raw spectra as well as the real database. To reduce the probability of false peptide identification, only peptides with significance scores $(\geq 20)$ at the $99 \%$ confidence interval as determined by a Mascot probability analysis were included. In addition, each confident protein identification involved at least one unique peptide. The quantitative protein ratios were weighted and normalized by the median ratio in Mascot. Statistical significance analyses were evaluated using two-way ANOVA. For comparison between 
samples, a protein with a ratio of mean fold change $>1.2$ (or $<0.83$ ) with an Exp pr $>0.05$ and a Group pr $<0.05$ was regarded as differentially expressed (Exp pr, three-experiment $p$-value; Group pr, group $p$-value; Fold Change $=$ Experiment + Group + Error).

Gene Ontology (GO) analysis was conducted using the Blast2GO program against the non-redundant protein database, and function characterization, biological network, pathway analysis were all performed using the Ingenuity Pathway Analysis software (IPA, http://www.ingenuity.com). The probable interacting partners were predicted using the STRING10 server (http://string.embl.de/). STRING is a database of both known and predicted protein-protein interactions. These include direct (physical) and indirect (functional) associations, which are derived from four separate sources: genomic context, highthroughput experiments, co-expression, and prior knowledge. A network was made at a medium confidence level (0.400), allowing all active prediction methods (Sharma et al., 2016).

\section{RNA Extraction and Real-Time PCR Analysis}

Total cellular RNA was extracted from MTBC-infected and mock-infected THP- 1 cells using the TRIzol reagent (Invitrogen) according to the manufacturer's protocol. After the RNA was reverse-transcribed to first-strand cDNA using oligo (dT) as the primer (Invitrogen), quantitative real-time PCR was performed using an Applied Biosystems ViiA 7 real-time PCR system. Reactions were each $10 \mu \mathrm{l}$ containing $50 \mathrm{ng}$ of cDNA, $2 \times$

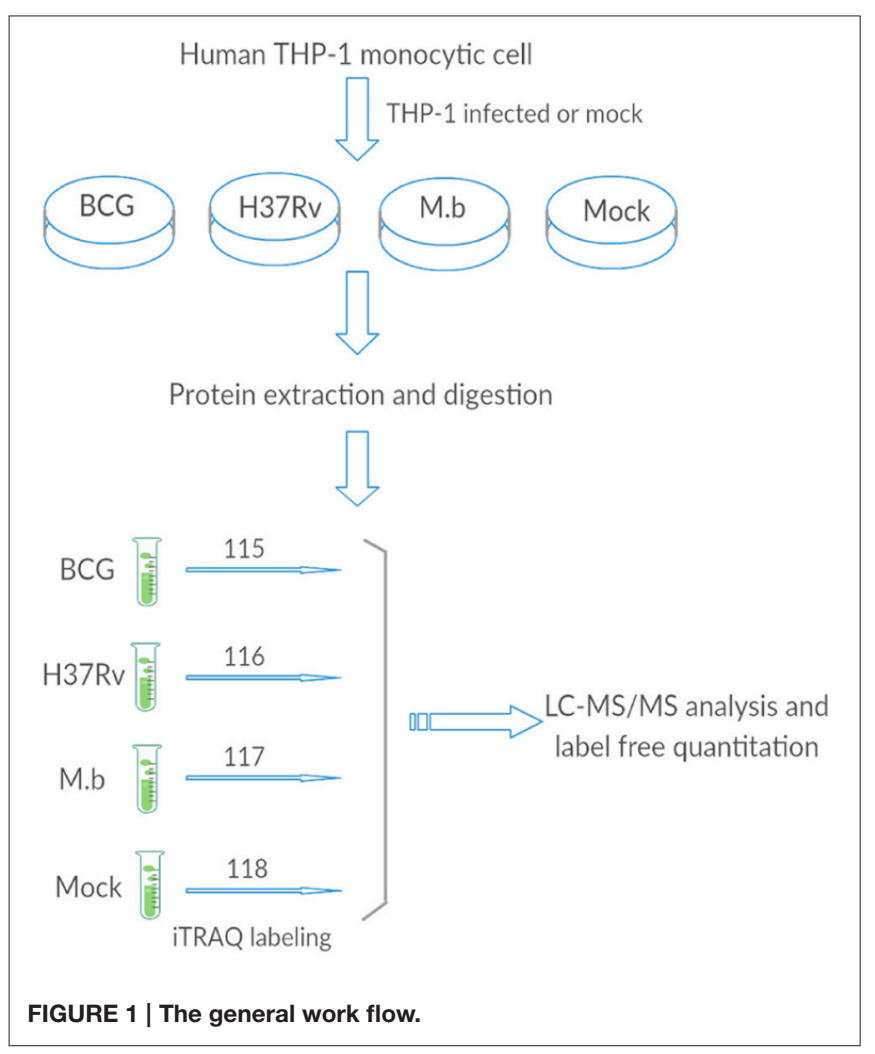

SYBR Green Master Mix Reagent (Applied Biosystems), and 100 $\mathrm{nM}$ of gene-specific primers. The thermocycling conditions were $95^{\circ} \mathrm{C}$ for $5 \mathrm{~min}$, and $40 \mathrm{cycles}$ at $95^{\circ} \mathrm{C}$ for $30 \mathrm{~s}, 60^{\circ} \mathrm{C}$ for $30 \mathrm{~s}$, and $72^{\circ} \mathrm{C}$ for $30 \mathrm{~s}$. Amplification specificity was assessed using melting curve analyses. Transcript abundances were normalized to GAPDH, which served as the internal control. The primers used are listed in Table S1. The degree of expression change was calculated using the $2^{-\Delta \Delta \mathrm{Ct}}$ method. Each cDNA sample was amplified in triplicate. The data analysis was performed also using the Applied Biosystems ViiA 7 real-time PCR system software (Applied Biosystems).

\section{Statistical Analysis}

All statistical analyses were performed using the GraphPad Prism software (version 6.02). Values are showed as mean \pm standard deviation (SD), $p<0.05$ was considered statistically significant.
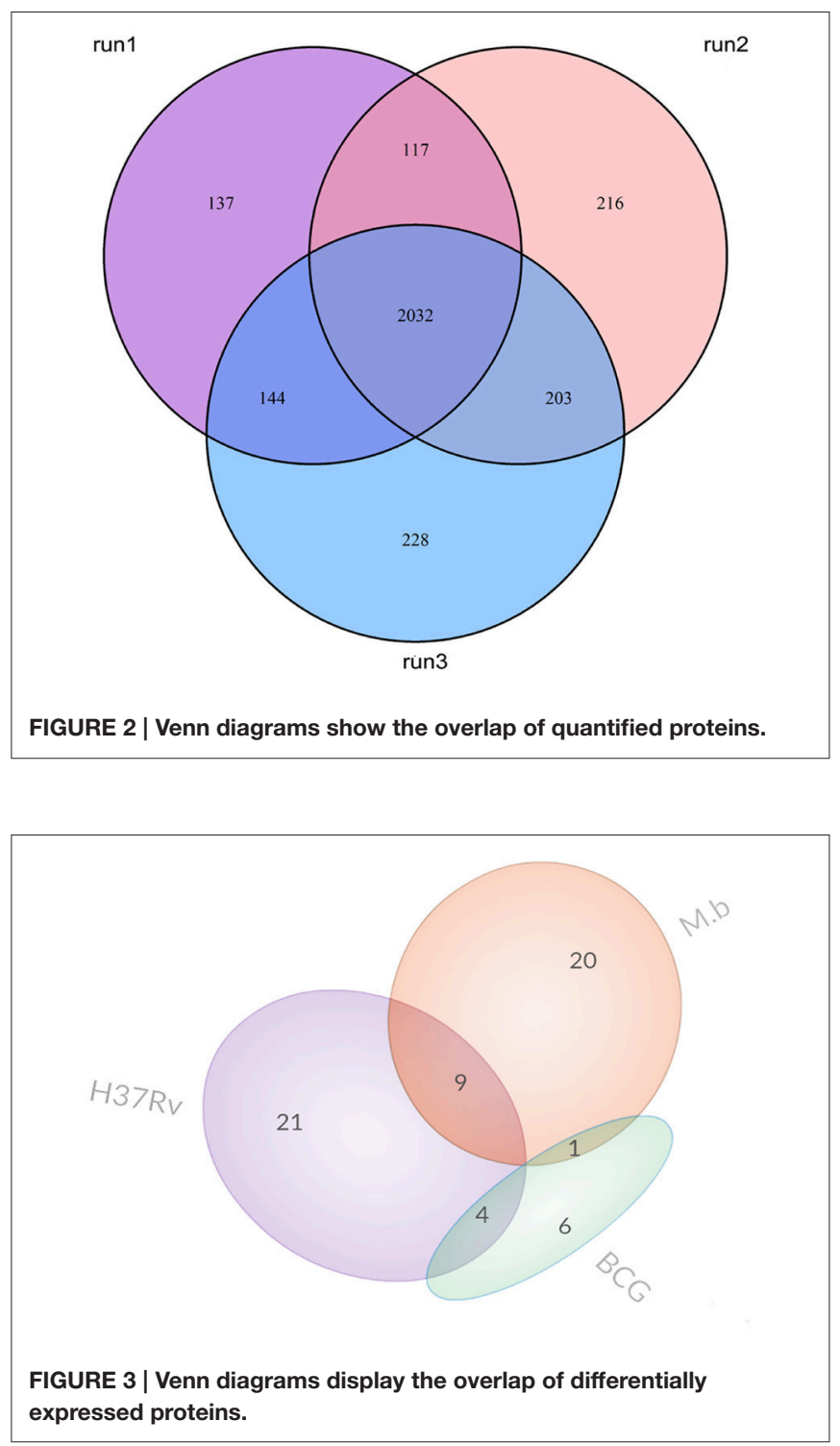


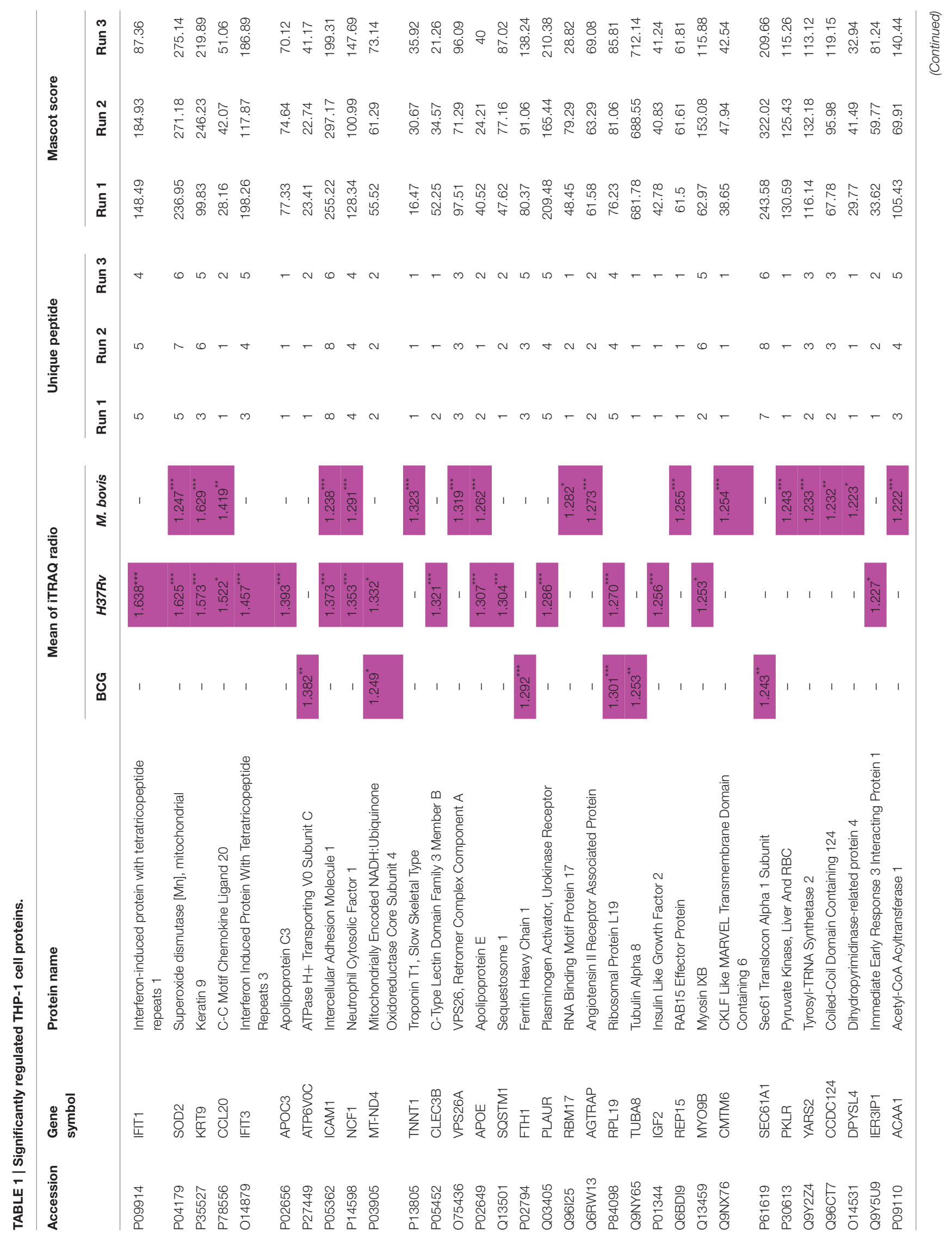




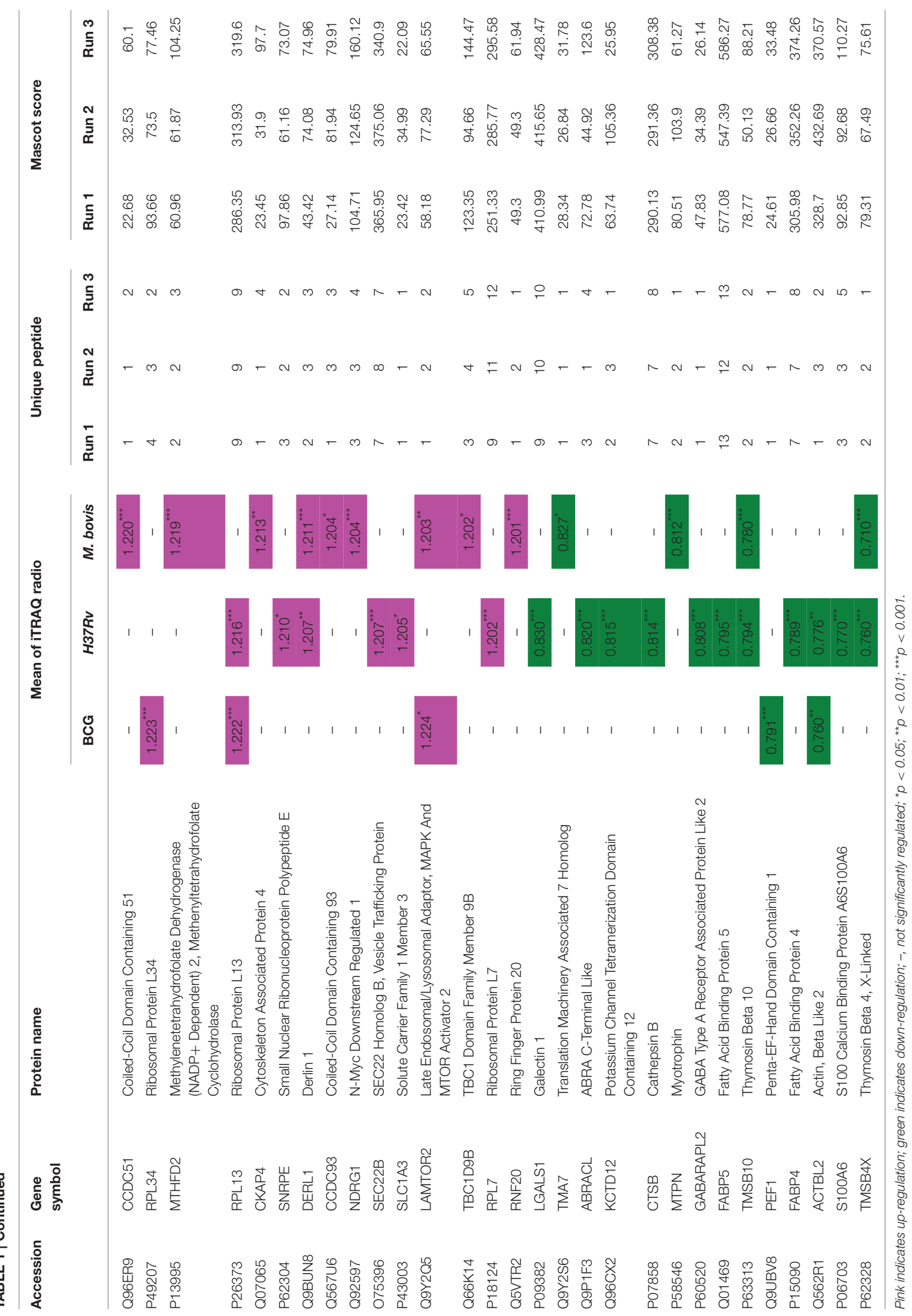




\section{RESULTS}

We employed label-free quantitative proteomics to analyze whole cell lysates harvested from THP-1 infected with either M. bovis, M. $t b-H 37 R v$, or BCG strains, and biological triplicates were performed (Figure 1). We quantified 2,032 proteins in each group, resulting in a total of 15,139 unique peptides from these 12 samples (we mock-infected cells also), however, 283 unique peptides were not detected in this study (Table S2).

\section{M. bovis, $H 37 R v$, and BCG Induce Different Host Protein Regulation}

In this study, we employed the use of human monocyte THP1 cells after first differentiating them with PMA. The iTRAQ data showed that a total of 2,481,2,569, and 2,608 proteins were quantified for three replicates, which were expressed as run 1, run 2 , and run 3, respectively (Figure 2). Among them, 2,032 proteins were common in all three biological replicates. Significant up/down regulations between samples were determined by a mean fold change $>1.2$ (or $<0.83$ ) with an Exp pr $>0.05$ and a Group pr $<0.05$ for peptide quantification. In total, 61 proteins were significantly up or down-regulated during MTBC infection (Figure 3).

Specifically, 26 proteins were up-regulated and 4 proteins were down-regulated during M. bovis infection. Meanwhile, 23 proteins were up-regulated and 11 proteins were down-regulated during $H 37 R v$ infection; 9 proteins were up-regulated and 2 proteins were down-regulated during BCG strain infection. In comparison with the uninfected cells, there was no common protein among those our MTBC-infected groups (Table 1).

Several common proteins were identified that altered host cells among our three strains. Only one host protein, regulator complex protein LAMTOR2, was up-regulated by $M$. bovis and BCG infections but not by H37Rv. Four host proteins (three were up-regulated and only ACTBL2 was down-regulated) were differentially regulated by $H 37 R v$ and BCG infections and not by $M$. bovis infection. The three up-regulated host proteins were RPL19, RPL13, and MT-ND4. Nine host proteins (seven were up-regulated and two were down-regulated) were differentially regulated by $H 37 R v$ and $M$. bovis infections but not by BCG infection. These seven up-regulated host proteins included ICAM1, APOE, CCL20, KRT9, DERL1, SOD2, and NCF1. The two down-regulated proteins were TMSB4X and TMSB10.

Several proteins were differentially regulated by variant sources of mycobacteria. M. bovis infection induced the upregulation of 19 proteins (including VPS26A, RBM17, REP15, CMTM6, YARS2, NDRG1, and RNF20), but H37Rv or BCG infection did not induce significant alterations in the levels of these proteins. Conversely, H37Rv infection induced the upregulation of two interferon-induced proteins (IFIT1 and IFIT3) and the down-regulation of eight other proteins (including

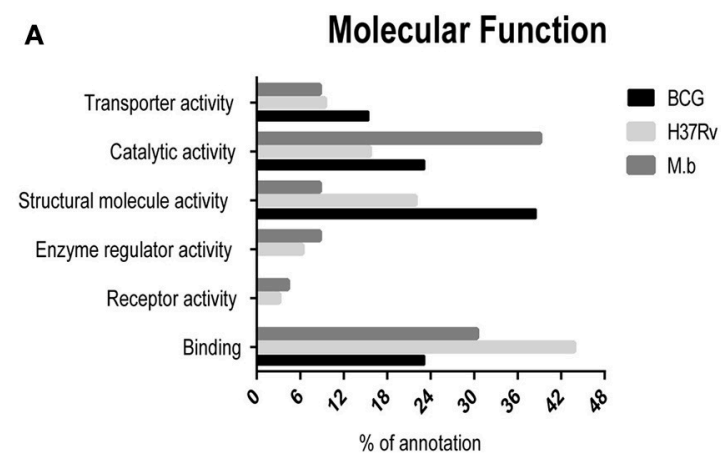

C

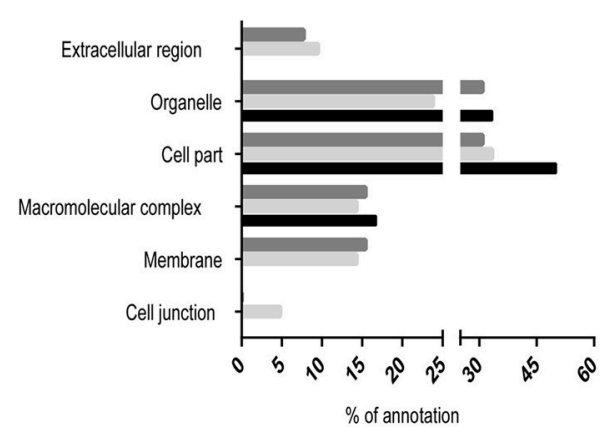

B Biological Process

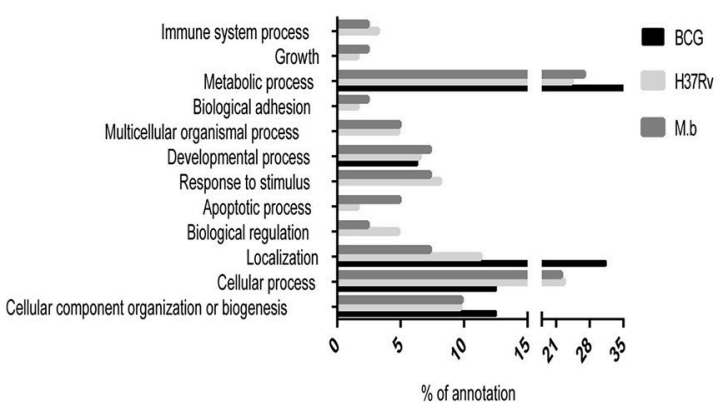

D

Protein Class

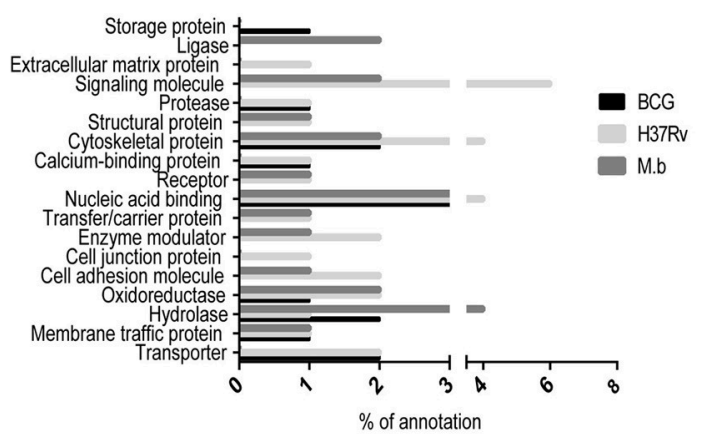

FIGURE 4 | Comparison of GO term annotation for significantly regulated proteins. (A) Molecular Function, (B) biological process, (C) cellular component, and (D) protein class. 
S100A6, FABP4, FABP5, GABARAPL2, and LGALS1), but $M$. bovis or BCG infection induced non-significant changes in the levels of these proteins. Meanwhile, five host proteins were differentially up-regulated (including ATP6V0C and SEC61A1), and only one was down-regulated (PEF1) by BCG infection but not by H37Rv or M. bovis infection.

\section{Functional Ontology Classification and Bioinformatics Analyses of Differentially Regulated Proteins}

The differentially expressed proteins were cataloged into different molecular functions (Figure 4A), biological processes
(Figure 4B), cellular components (Figure 4C), and protein class (Figure 4D) by searching the Gene Ontology and Uniprot databases. Differentially regulated $M$. bovis-infected cell proteins were found to mainly localize to metabolism, enzymatic activity, and cell part. Among 34 modulated proteins in the $H 37 R v$-infected samples, these proteins were mainly implicated in metabolic processes, as well as BCG-induced host proteins. Together, the GO annotation comparison provided a comprehensive overview of differences regarding THP-1 infected with virulent $H 37 R v$ and $M$. bovis strains and the BCG vaccine strain, proteins which may be important in TB pathogenesis and transmission.

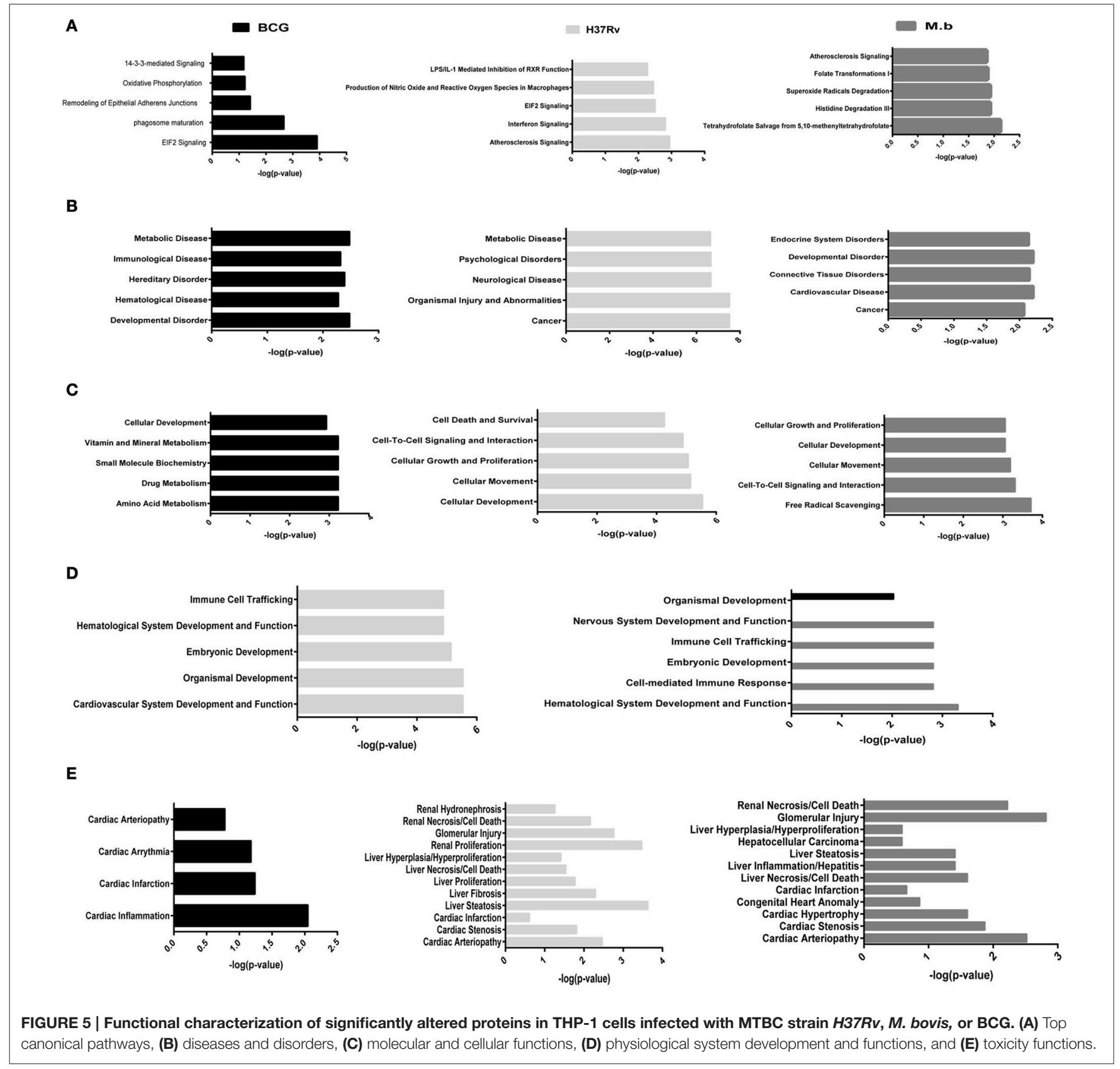


A

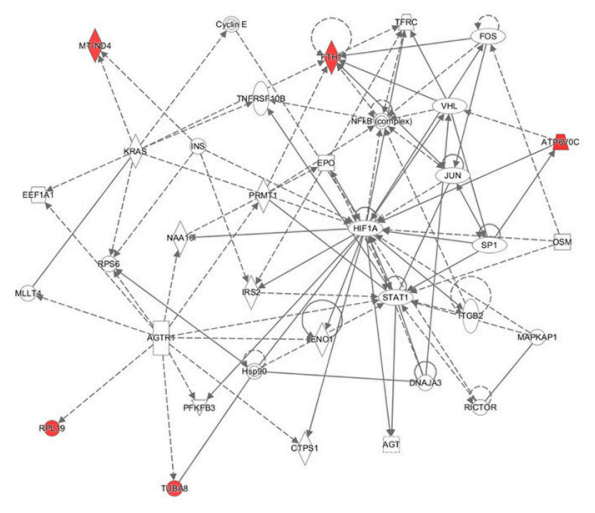

B
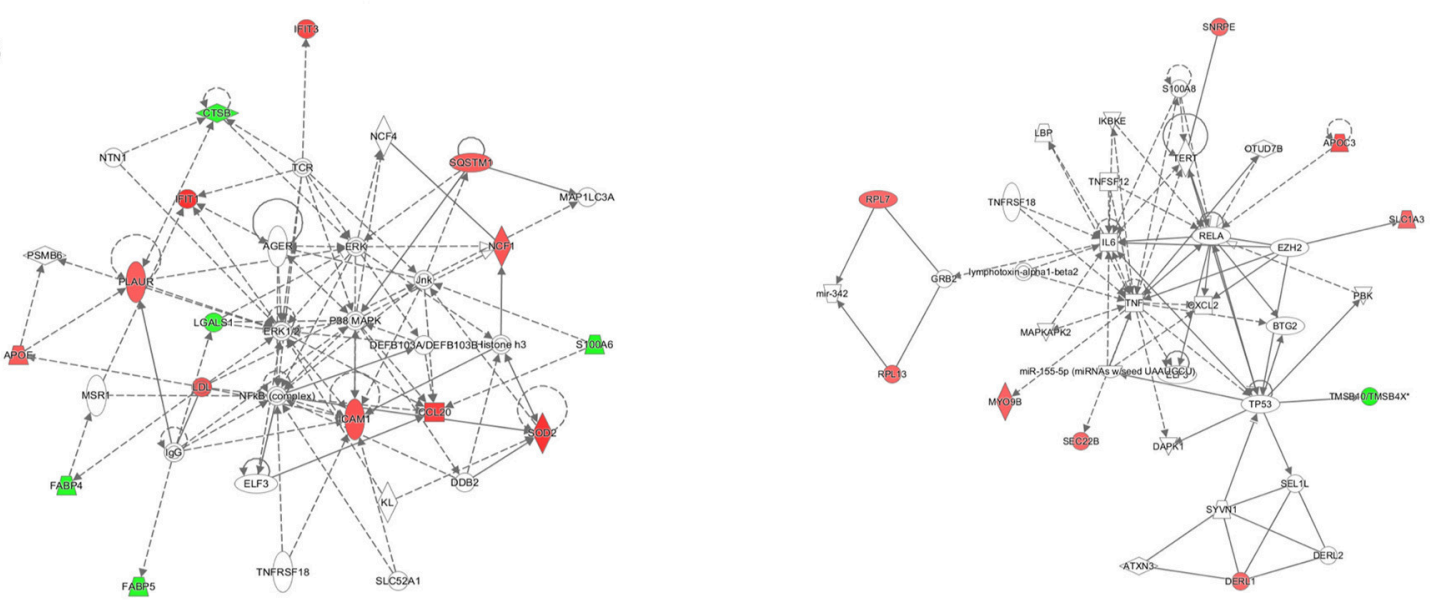

C
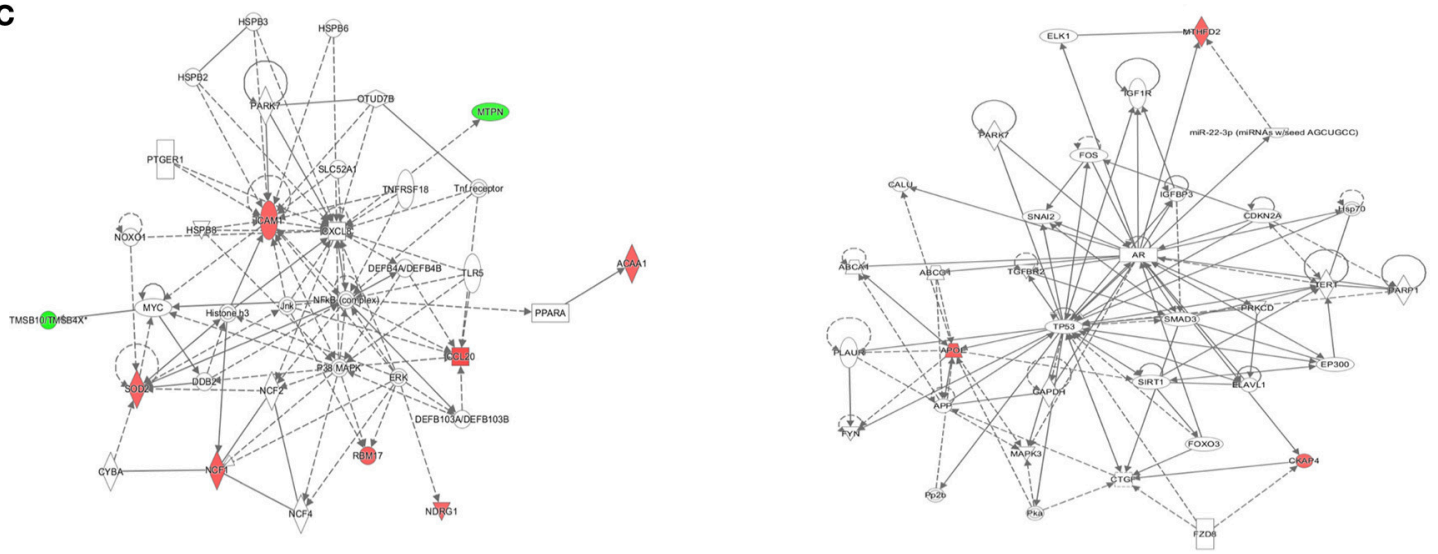

FIGURE 6 | The detailed view of the top-score networks. Red indicates significantly up-regulated proteins, and green indicates significantly down-regulated proteins. White indicates the proteins that were not identified in our data. The color depth reflects the fold-change of proteins. The shapes are indicative of the molecular class. Lines with arrows connecting between the molecules indicate molecular relationships. Solid lines indicate direct interactions, and dashed lines indicate indirect interactions. (A) The top-score IPA network of BCG infection: cellular development, cellular growth and proliferation, cell death and survival, (B) the top two IPA networks of H37Rv infection: cellular movement, hematological system development and function, and immune cell trafficking (left); cancer, cell death, and survival, and cellular movement (right), (C) the top two IPA networks of $M$. bovis infection: free radical scavenging, hereditary disorder, and immunological disease (left); cell death and survival, organismal injury and abnormalities, and tissue morphology (right). Additional networks are depicted in Table $\mathbf{S 4 .}$ 
To better analyze the function characterization and biological processes of relevant proteins, the Uniprot accession numbers and ratios (+Strain/Mock) of all differentially expressed proteins were uploaded into the IPA software. According to the function classification, all the differentially expressed proteins could be classified into five distinctive functional settings: (A) top canonical pathways; (B) diseases and disorders; (C) molecular and cellular functions; (D) physiological system development and functions; (E) toxicity Functions (shown in Figure 5 and Table S3, $p<0.05$ ). These proteins were involved in various biological processes and functions, including cancer, immune cell trafficking, immunological disease, inflammatory disease, cell death and survival, protein trafficking, metabolic disease, cell-to-cell signaling and interaction, and infectious diseases. To note, immunological disease, as well as inflammatory response and disease, were more prominent upon infection of cells with virulent $H 37 R v$ and $M$. bovis than the BCG strain.

The IPA tool was used to explore the potential, specific functional networks for proteins that changed in abundance. In total, 38 protein networks were mapped based on these differentially regulated proteins upon $M$. bovis, $H 37 R v$, and BCG infection, respectively (Table S4). To investigate the underlying biologically functional differences that may be related to MTBC infection, five strongly represented networks of interest were depicted. For BCG infection, the top-score network was cellular development, cellular growth and proliferation, cell death and survival (5 molecules; score 11; Figure 6A). For $H 37 R v$ infection, the top two networks were: (1) cellular movement, hematological system development and function, and immune cell trafficking (14 molecules; score 29; Figure 6B, left); and (2) cancer, cell death, and survival, and cellular movement ( 9 molecules; score 16; Figure 6B, right). For M. bovis infection, the top two networks were: (1) free radical scavenging, hereditary disorder, and immunological disease (9 molecules; score 18; Figure 6C, left); (2) cell death and survival, organismal injury and abnormalities, and tissue morphology (3 molecules; score 5; Figure 6C, right). All networks showed significant differences in the specific members that were up-regulated, un-regulated, or down-regulated upon BCG, $H 37 R v$, or M. bovis infection.

Similarly, IPA analysis identified numerous significantlyaffected canonical pathways. The phagosome maturation pathway was differentially affected by BCG and H37Rv treatments (Figure S1A). Moreover, several proteins were similarly regulated by virulent $H 37 R v$ and $M$. bovis: differentially regulated proteins CCL20 and ICAM1, both involved in the TNF signaling pathway (Figure S1B); differentially regulated proteins NCF1 and ICAM1, both involved in the leukocyte transendothelial migration pathway (Figure S1C). Additional representative canonical pathways, such as EIF2 signaling, rheumatoid arthritis, PPAR signaling pathway, SNARE interactions in vesicular transport, peroxisome, and chemokine signaling pathway, were also differentially regulated upon infection (Table S5).

\section{String Analysis}

The 60 differently expressed proteins were analyzed using STRING-10 with a medium confidence score threshold

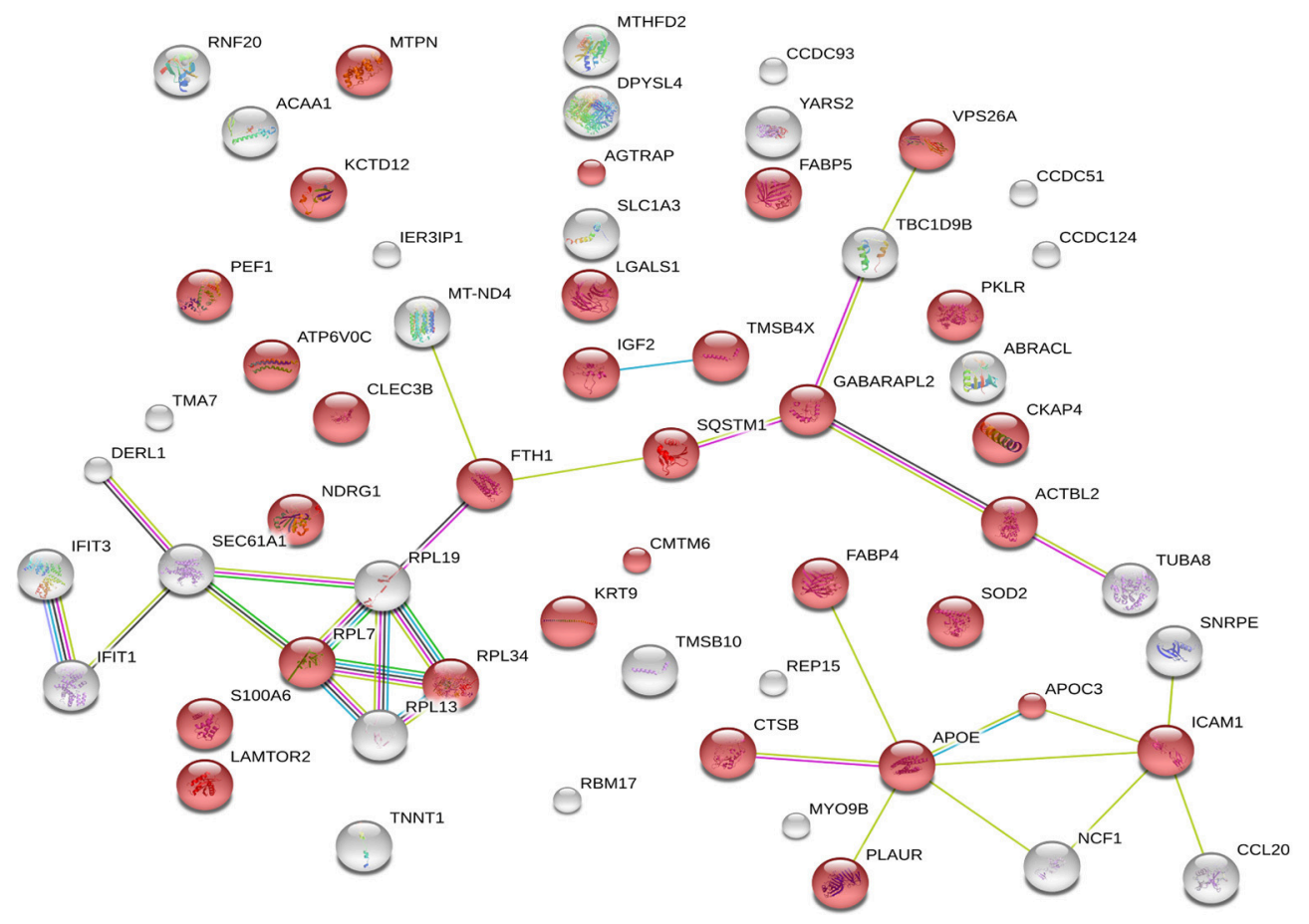

FIGURE 7 | STRING analysis revealing the interaction partners of the significantly altered proteins. Red color indicates 31 proteins involved in vesicle category. 
of 0.4 , and an interactome network was built for these set of proteins to find out protein-protein interaction and predict functional associations. We found that proteins involved in signaling pathway, migration pathway, vesicular transport, and intermediary metabolism interacted with each other as well as their partners; in addition, SEC22b cannot be founded by STRING-10. We also found that 31 proteins were involved in vesicle category and that most of them interacted with each other as well as their partners (Figure 7).

\section{Quantitative Real-Time (qRT)-PCR Validation}

To confirm the differential expression of the cellular proteome during MTBC-infection, 28 genes based on interest and different ratios were selected and assessed via qRT-PCR (Figure 8). The ratios from qRT-PCR analysis were in accordance with those obtained from the iTRAQ approach.

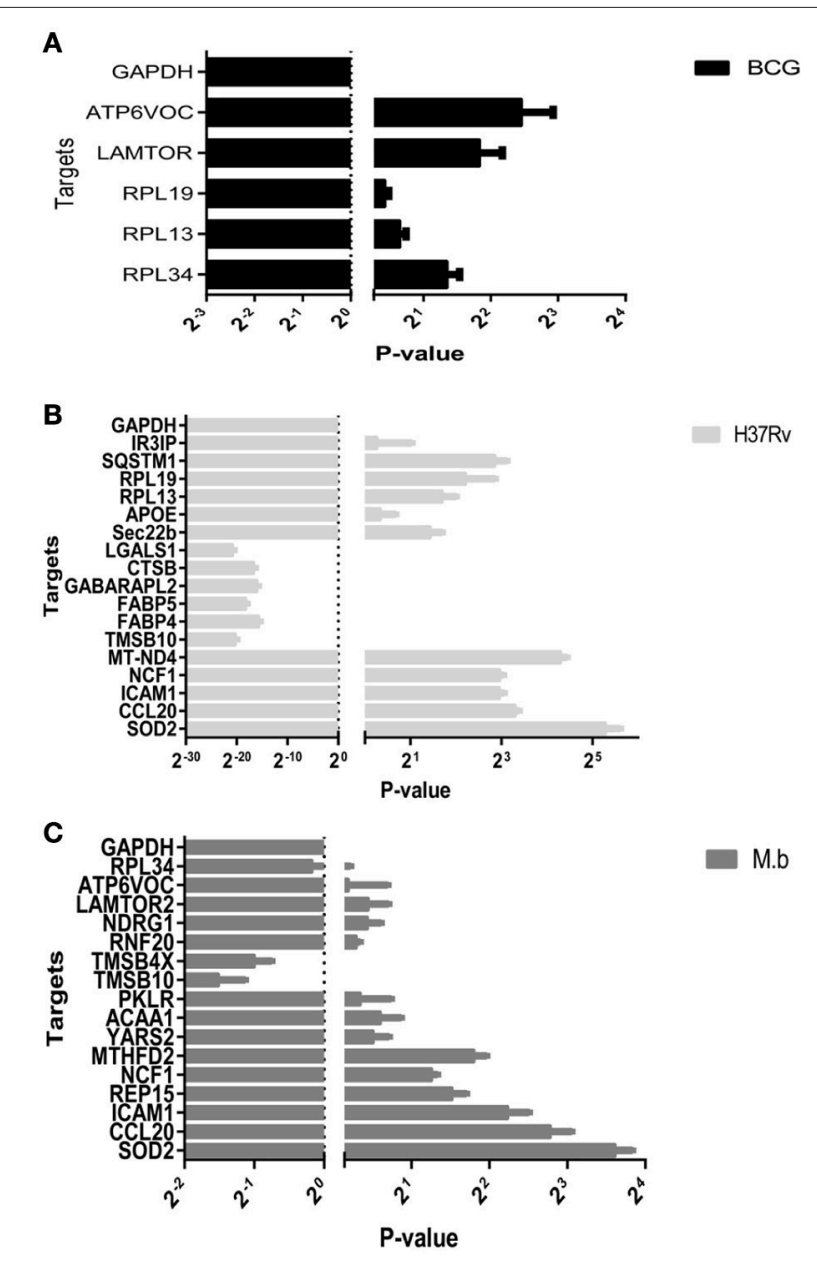

FIGURE 8 | Real-time RT-PCR analysis of significantly altered proteins in THP-1 cells infected by MTBC (10 MOI) or a mock. (A) BCG in black bars, (B) H37Rv in gray bars, (C) M. bovis in dark gray bars.

\section{DISCUSSION}

To date, the proteomics field has increasingly focused on intrinsically different proteins during host-pathogen interactions induced by MTBC infection. A variety of proteomic approaches have been applied to cells stimulated by infection (Rao et al., 2009; Li et al., 2011; Kaewseekhao et al., 2015; Saquib et al., 2015; Diaz et al., 2016; Long et al., 2016) or mycobacterial bioactive lipids (Shui et al., 2008). Comparisons of the results obtained in the current study with a previous proteomic assay of the BCG infected THP-1 cell (Lee et al., 2010) indicated that 392 common proteins and were identified and measured in both studies. There was good correlation between the two studies: 367 proteins were indicated as not significantly regulated in both assays and no proteins were indicated as significantly up-regulated in one assay but down-regulated in the other. Interestingly, lysosome-associated protein- LAMP-2 was tested as well as LAMTOR2 is discovered up- regulated in present BCG-infected cell study. There was no common protein comfirmed as significantly regulated in both studies, partly because the different time and method for purification of BCG phagosomes. Remarkably, differentially regulated proteins in these studies were associated with hemopoiesis, vesicle transport, apoptosis, phagosome maturation, immune cell trafficking, and the inflammatory response. Not all processes were affected by all MTBC strains or in different cell type, especially the virulent M. bovis-human host interaction. Thus, the current study was conducted to directly compare a live vaccine strain and two virulent strains, $H 37 R v$ and $M$. bovis, in a common cell type that had been previously used.

It is known that different MTB genetic groups can exhibit different features that affect protein extraction (Bespyatykh et al., 2016). The well-studied laboratory $H 37 R v$ strain cultured in cell culture media shows no net increase in viable bacilli numbers out to 7 days (Ackart et al., 2014). Because we used the same workflow both for three different strains, to be sure of its effectiveness we compared the number of identifed proteins within functional categories. It allows us to conclude that the differences in protein abundance we observed from MTBCinfection are independent from our workflow and reflect the true physiological characteristics of pathogens. Upon cellular infection, the two virulent strains induced host alterations were major differences in the proteins and pathways, comparing responses to mock and vaccine strain BCG. It was shown that SOD2, KTR9, CCL20, and ICAM1 were significantly upregulated by $H 37 R v$ and $M$. bovis infections. Moreover, two of these proteins, CCL20 and ICAM1 which involved the TNF signaling pathway, were prominently upregulated at the mRNA level via qRT-PCR (Figure 8). The group of virulence $H 37 R v$ infection showed a higher dysregulation distribution of proteins across functional categories, in agreement with the results of $\mathrm{Li}$ et al. (2011).

Global protein analyses of the post translational modifications (PTMs) have deciphered that PTMs are associated with pathogenicity in bacteria, including phosphorylation (Calder et al., 2016), lysine succinylation (Yang et al., 2015), and glycosylation (Hare et al., 2017). It is striking that IFIT1 and 
IFIT3, two interferon-induced proteins involved in interferon signaling (Hare et al., 2015, 2017), showed significant upregulation among the $H 37 R v$-induced proteins. Moreover, several proteins involved in PTMs were differently regulated by M. bovis-infection, including RNF20, YARS2, and TMSB10 (Table 1). A study has demonstrated that LprG of $M$. bovis interacted with LAMP-3 to modulate the traffic machinery in cells (Vázquez et al., 2016). LAMTOR2 might be a potential target for endosome trafficking events of $M$. bovis by interacting with bacterial proteins. Since a small amount of enzyme can promote high efficiency response, the enzyme MTHFD2, SOD2, YARS2, and RNF20 were differentially regulated during $M$. bovis infection. Moreover, two of these proteins, SOD2 and MTHFD2 which involved in metabolism pathways, were prominently upregulated at the mRNA level via qRT-PCR (Figure 8). Particularly, the analysis of canonical pathways revealed that bifunctional methylenetetrahydrofolate dehydrogenase (MTHFD2) was involved in the pathways "tetrahydrofolate salvage from 5,10-methenyltetrahydrofolate, histidine degradation III, and folate transformations I" and can directly interact with each other (Figure 6C, right), suggesting that MTHFD2 enzyme is effective upon $M$. bovis infection.
Among the 61 differently regulated proteins, the interactome network revealed that 27 proteins interacted with each other. The vacuolar protein VPS26A, involved in endocytosis, interacted with TBC1D9B uniquely induced by $M$. bovis. Meanwhile, five common proteins induced by virulence strains- $M$. $t b$ and $M$. bovis involved in signaling pathway interacted with each other (Figure 9). Our findings have contributed to a large number of cellular proteins that are differentially regulated by $M . t b$ and $M$. bovis.

The successful establishment and maintenance of bacterial infection not only depends on the pathogenic bacteria's ability but also the host cell's defense response. Different strains of the same species can also induce differences in pathology (Price et al., 2003; Jeon et al., 2008; Shah et al., 2013; Bai et al., 2015; Zhou et al., 2016). The present proteomic profiles of cellular proteins are beneficial to improving and enhancing understanding of the existing network of cross-talk mechanisms between the host and pathogen (Sambarey et al., 2013; Wu et al., 2014; Diaz et al., 2016; Li et al., 2016; Vázquez et al., 2016).

In conclusion, our study presents for the first application of proteomic analysis to compare whole cellular protein alterations induced by virulent $M$. bovis infections. The lysosomal adaptor

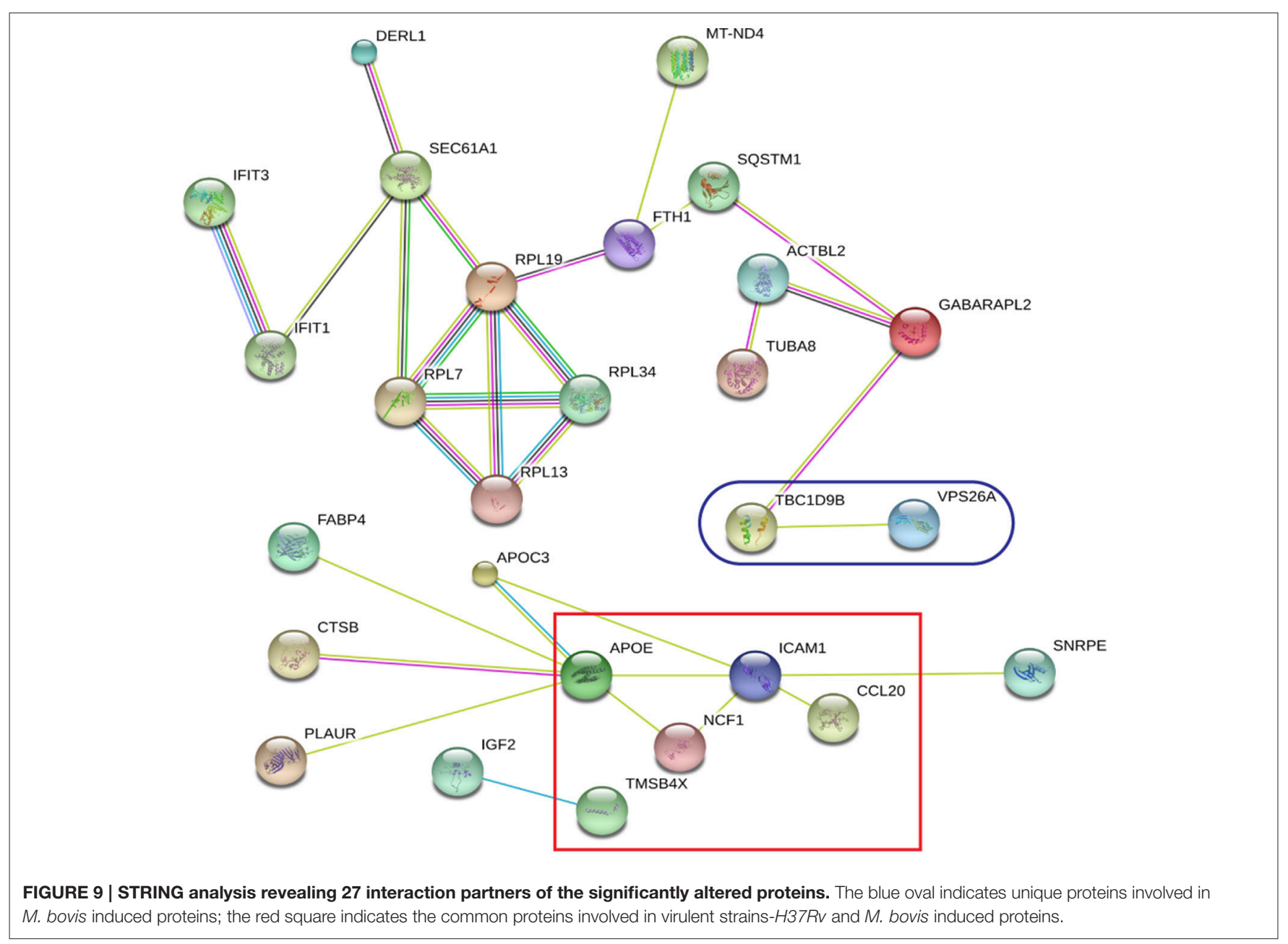


LAMTOR2 might be a potential target for endosome trafficking events of $M$. bovis. The MTHFD2, VPS26A, and TBC1D9B proteins uniquely induced by virulent $M$. bovis infections might reveal novel biomarkers, which are also critical in cattleto-human transmission and diagnosis of TB. Even though our fndings do not have an immediate proofs to elucidate the mechanism of how $M$. bovis interact with the host, they represent the proof-of-concept that virulent $M$. bovis will induce human cells with a characteristic proteome. To further characterize the intimate and persistent connection between these common mycobacterial pathogens, we will still need to molecularly explore the host-pathogen landscape, identify molecules with anti-TB function, and determine the means to clinically treat based on insight gleaned from pathogen-host interactions at both a global and a targeted level.

\section{AUTHOR CONTRIBUTIONS}

$\mathrm{CT}$ and $\mathrm{HC}$ designed experiments, PL wrote the manuscript. PL, RW, WD, LH, BZ and YZ performed the experiments. All authors analyzed and interpreted data. YX, AZ, AG, and XW participated in the interpretation and discussion of the results. All authors read and approved the final manuscript.

\section{FUNDING}

This work was supported by grants from the National Natural Science Foundation of China (NSFC) (No. 31421064), the National Key Research and Development Program of China and

\section{REFERENCES}

Ackart, D. F., Hascall-Dove, L., Caceres, S. M., Kirk, N. M., Podell, B. K., and Melander, C. (2014). Expression of antimicrobial drug tolerance by attached communities of Mycobacterium tuberculosis. Pathog. Dis. 70, 359-369. doi: 10.1111/2049-632X.12144

Arbues, A., Lugo-Villarino, G., Neyrolles, O., Guilhot, C., and Astarie-Dequeker, C. (2015). Playing hide-and-seek with host macrophages through the use of mycobacterial cell envelope phthiocerol dimycocerosates and phenolic glycolipids. Front. Cell. Infect. Microbiol. 4:173. doi: 10.3389/fcimb.2014.00173

Ayele, W. Y., Neill, S. D., Zinsstag, J., Weiss, M. G., and Pavlik, I. (2004). Bovine tuberculosis: an old disease but a new threat to Africa. Int. J. Tuberculosis Lung Dis. 8, 924-937.

Bai, X., Kinney, W. H., Su, W. L., Bai, A., Ovrutsky, A. R., Honda, J. R., et al. (2015). Caspase-3-independent apoptotic pathways contribute to interleukin$32 \gamma$-mediated control of Mycobacterium tuberculosis infection in THP- 1 cells. BMC Microbiol. 15:39. doi: 10.1186/s12866-015-0366-z

Bespyatykh, J., Shitikov, E., Butenko, I., Altukhov, I., Alexeev, D., Mokrousov, I., et al. (2016). Proteome analysis of the Mycobacterium tuberculosis Beijing B0/W148 cluster. Sci. Rep. 6:28985. doi: 10.1038/srep28985

Bigi, M. M., Blanco, F. C., Araújo, F. R., Thacker, T. C., Zumárraga, M. J., and Cataldi, A. A. (2016). Polymorphisms of 20 regulatory proteins between Mycobacterium tuberculosis and Mycobacterium bovis. Microbiol. Immunol. 60, 552-560. doi: 10.1111/1348-0421.12402

Blanco, F. C., Bigi, F., and Soria, M. A. (2014). Identification of potential biomarkers of disease progression in bovine tuberculosis. Vet. Immunol. Immunopathol. 160, 177-183. doi: 10.1016/j.vetimm.2014.04.008 the Hubei Province Natural Science Foundation for Innovative Research Groups (2016CFA015).

\section{ACKNOWLEDGMENTS}

We thank Dr. Chuan-You Li from Beijing Tuberculosis \& Thoracic Tumor Research Institute for kindly providing the $M$. $t b$ and M. bovis strains, and Mr. Z. G. Liang for use of the BSL-3 facilities.

\section{SUPPLEMENTARY MATERIAL}

The Supplementary Material for this article can be found online at: http://journal.frontiersin.org/article/10.3389/fcimb. 2017.00065/full\#supplementary-material

Figure S1 | Significantly affected canonical pathways determined by IPA ${ }^{\circledR}$ analysis. Red indicates up-regulated proteins, light green indicates down-regulated proteins, gray represents not significantly affected proteins, and white represents proteins known to be part of the pathways but not identified by ITRAQ. (A) The phagosome maturation pathway is differentially affected by BCG and H37Rv treatments, (B) the TNF signaling pathway is similarly regulated by virulent $H 37 R v$ and $M$. bovis, (C) the leukocyte transendothelial migration pathway is similarly regulated by virulent $H 37 R v$ and $M$. bovis. Examples of additional affected canonical pathways are depicted in Table S5.

Table S1 | List of real-time RT-PCR primers used in this study.

Table S2 | List of the 2,032 unique proteins detected our study. Exp pr, three-experiment $p$-value; Group pr, group $p$-value.

Table S3 | Functional classification of 61 differentially expressed proteins.

Table S4 | Network analysis of 38 differentially expressed proteins.

Table S5 | Canonical pathway analysis of differentially expressed proteins.

Calder, B., Albeldas, C., Blackburn, J. M., and Soares, N. C. (2016). Mass spectrometry offers insight into the role of Ser/Thr/Tyr phosphorylation in the mycobacteria. Front. Microbiol. 7:141. doi: 10.3389/fmicb.2016.00141

Chandran, A., Antony, C., Jose, L., Mundayoor, S., Natarajan, K., and Kumar, R. A. (2015). Mycobacterium tuberculosis infection induces HDAC1-mediated suppression of IL-12B gene expression in macrophages. Front. Cell. Infect. Microbiol. 5:90. doi: 10.3389/fcimb.2015.00090

Chen, Y., Wu, J., Tu, L., Xiong, X., Hu, X., and Huang, J. (2013). 1 H-NMR spectroscopy revealed Mycobacterium tuberculosis caused abnormal serum metabolic profile of cattle. PLoS ONE 8:e74507. doi: 10.1371/journal.pone.0074507

Colonne, P. M., Winchell, C. G., and Voth, D. E. (2016). Hijacking host cell highways: manipulation of the host actin cytoskeleton by obligate intracellular bacterial pathogens. Front. Cell. Infect. Microbiol. 6:107. doi: $10.3389 /$ fcimb.2016.00107

Cosivi, O., Grange, J. M., Daborn, C. J., Raviglione, M. C., Fujikura, T., Cousins, D., et al. (1998). Zoonotic tuberculosis due to Mycobacterium bovis in developing countries. Emerg. Infect. Dis. 4:59. doi: 10.3201/eid0401.980108

Cosivi, O., Meslin, F. X., Daborn, C. J., and Grange, J. M. (1995). Epidemiology of Mycobacterium bovis infection in animals and humans, with particular reference to Africa. Rev. Sci. Tech. 14, 733-746.

Cosma, C. L., Sherman, D. R., and Ramakrishnan, L. (2003). The secret lives of the pathogenic mycobacteria. Ann. Rev. Microbiol. 57, 641-676. doi: 10.1146/annurev.micro.57.030502.091033

Davis, J. M., and Ramakrishnan, L. (2009). The role of the granuloma in expansion and dissemination of early tuberculous infection. Cell 136, 37-49. doi: $10.1016 / j . c e l l .2008 .11 .014$ 
Diaz, G., Wolfe, L. M., Kruh-Garcia, N. A., and Dobos, K. M. (2016). Changes in the membrane-associated proteins of exosomes released from human macrophages after Mycobacterium tuberculosis infection. Sci. Rep. 6:37975. doi: $10.1038 /$ srep37975

Dye, C., and Williams, B. G. (2010). The population dynamics and control of tuberculosis. Science 328, 856-861. doi: 10.1126/science.1185449

El-Sayed, A., El-Shannat, S., Kamel, M., Castañeda-Vazquez, M. A., and CastañedaVazquez, H. (2016). Molecular epidemiology of Mycobacterium bovis in humans and cattle. Zoonoses Public Health 63, 251-264. doi: 10.1111/zph.12242

Ernst, J. D., Trevejo-Nuñez, G., and Banaiee, N. (2007). Genomics and the evolution, pathogenesis, and diagnosis of tuberculosis. J. Clin. Invest. 117, 1738-1745. doi: 10.1172/JCI31810

Esterhuyse, M. M., Weiner, J., Caron, E., Loxton, A. G., Iannaccone, M., Wagman, C., et al. (2015). Epigenetics and proteomics join transcriptomics in the quest for tuberculosis biomarkers. Mbio 6, e01187-e01115. doi: $10.1128 / \mathrm{mBio} 01187-15$

Fogel, N. (2015). Tuberculosis: a disease without boundaries. Tuberculosis 95, 527-531. doi: 10.1016/j.tube.2015.05.017

Gallivan, M., Shah, N., and Flood, J. (2015). Epidemiology of human Mycobacterium bovis disease, California, USA, 2003-2011. Emerg. Infect. Dis. 21:435. doi: 10.3201/eid2103.141539

Garnier, T., Eiglmeier, K., Camus, J. C., Medina, N., Mansoor, H., Pryor, M., et al. (2003). The complete genome sequence of Mycobacterium bovis. Proc. Natl. Acad. Sci. U.S.A. 100, 7877-7882. doi: 10.1073/pnas.1130426100

Garton, N. J., Waddell, S. J., Sherratt, A. L., Lee, S. M., Smith, R. J., Senner, C., et al. (2008). Cytological and transcript analyses reveal fat and lazy persister-like bacilli in tuberculous sputum. PLoS Med. 5:e75. doi: 10.1371/journal.pmed.0050075

Giri, P. K., Kruh, N. A., Dobos, K. M., and Schorey, J. S. (2010). Proteomic analysis identifies highly antigenic proteins in exosomes from M. tuberculosis-infected and culture filtrate protein-treated macrophages. Proteomics 10, 3190-3202. doi: 10.1002/pmic. 200900840

Hare, N. J., Chan, B., Chan, E., Kaufman, K. L., Britton, W. J., and Saunders, B. M. (2015). Microparticles released from Mycobacterium tuberculosisinfected human macrophages contain increased levels of the type I interferon inducible proteins including ISG15. Proteomics 15, 3020-3029. doi: 10.1002/pmic. 201400610

Hare, N. J., Lee, L. Y., Loke, I., Britton, W. J., Saunders, B. M., and ThaysenAndersen, M. (2017). Mycobacterium tuberculosis infection manipulates the glycosylation machinery and the N-glycoproteome of human macrophages and their microparticles. J. Proteome Res. 16, 247-263. doi: 10.1021/acs.jproteome.6b00685

He, Y., Li, W., Liao, G., and Xie, J. (2012). Mycobacterium tuberculosis-specific phagosome proteome and underlying signaling pathways. J. Proteome Res. 11, 2635-2643. doi: 10.1021/pr300125t

Hmama, Z., Gabathuler, R., Jefferies, W. A., de Jong, G., and Reiner, N. E. (1998). Attenuation of HLA-DR expression by mononuclear phagocytes infected with Mycobacterium tuberculosis is related to intracellular sequestration of immature class II heterodimers. J. Immunol. 161, 4882-4893.

Hsu, T., Hingley-Wilson, S. M., Chen, B., Chen, M., Dai, A. Z., Morin, P. M., et al. (2003). The primary mechanism of attenuation of bacillus Calmette-Guerin is a loss of secreted lytic function required for invasion of lung interstitial tissue. Proc. Natl. Acad. Sci. U.S.A. 100, 12420-12425. doi: 10.1073/pnas.1635213100

Jamwal, S., Midha, M. K., Verma, H. N., Basu, A., Rao, K. V., and Manivel, V. (2013). Characterizing virulence-specific perturbations in the mitochondrial function of macrophages infected with Mycobacterium tuberculosis. Sci. Rep. 3:1328. doi: 10.1038/srep01328

Jeon, B. Y., Derrick, S. C., Lim, J., Kolibab, K., Dheenadhayalan, V., Yang, A. L., et al. (2008). Mycobacterium bovis BCG immunization induces protective immunity against nine different Mycobacterium tuberculosis strains in mice. Infect. Immun. 76, 5173-5180. doi: 10.1128/IAI.00019-08

Jiang, G., Wang, G., Chen, S., Yu, X., Wang, X., Zhao, L., et al. (2015). Pulmonary tuberculosis caused by Mycobacterium bovis in China. Sci. Rep. 5:8538. doi: 10.1038/srep08538

Kaewseekhao, B., Naranbhai, V., Roytrakul, S., Namwat, W., Paemanee, A., Lulitanond, V., et al. (2015). Comparative proteomics of activated THP-1 cells infected with Mycobacterium tuberculosis identifies putative clearance biomarkers for tuberculosis treatment. PLoS ONE 10:e0134168. doi: 10.1371/journal.pone.0134168

Koul, A., Arnoult, E., Lounis, N., Guillemont, J., and Andries, K. (2011). The challenge of new drug discovery for tuberculosis. Nature 469, 483-490. doi: 10.1038/nature09657

Kumar, D., Nath, L., Kamal, M. A., Varshney, A., Jain, A., Singh, S., et al. (2010). Genome-wide analysis of the host intracellular network that regulates survival of Mycobacterium tuberculosis. Cell 140, 731-743. doi: $10.1016 /$ j.cell.2010.02.012

Kunnath-Velayudhan, S., and Porcelli, S. A. (2013). Recent advances in defining the immunoproteome of Mycobacterium tuberculosis. Front. Immunol. 4:335. doi: 10.3389/fimmu.2013.00335

Lamont, E. A., Janagama, H. K., Ribeiro-Lima, J., Vulchanova, L., Seth, M., Kurmi, K., et al. (2014). Circulating Mycobacterium bovis peptides and host response proteins as biomarkers for unambiguous detection of subclinical infection. $J$. Clin. Microbiol. 52, 536-543. doi: 10.1128/JCM.02433-13

Lee, B. Y., Jethwaney, D., Schilling, B., Clemens, D. L., Gibson, B. W., and Horwitz, M. A. (2010). The Mycobacterium bovis bacille Calmette-Guerin phagosome proteome. Mol. Cell. Proteomics 9, 32-53. doi: 10.1074/mcp.M900396MCP200

Li, C., Lee, Y., and Chen, B. S. (2016). Genetic-and-epigenetic interspecies networks for cross-talk mechanisms in human macrophages and dendritic cells during MTB infection. Front. Cell. Infect. Microbiol. 6:124. doi: $10.3389 /$ fcimb.2016.00124

Li, Q., Singh, C. R., Ma, S., Price, N. D., and Jagannath, C. (2011). Labelfree proteomics and systems biology analysis of mycobacterial phagosomes in dendritic cells and macrophages. J. Proteome Res. 10, 2425-2439. doi: $10.1021 / \mathrm{pr} 101245 \mathrm{u}$

Long, J., Roy, R. B., Zhang, Y. J., Antrobus, R., Du, Y., and Smith, D. L. (2016). Plasma membrane profiling reveals upregulation of ABCA1 by infected macrophages leading to restriction of mycobacterial growth. Front. Microbiol. 7:1086. doi: 10.3389/fmicb.2016.01086

López, V., Villar, M., Queirós, J., Vicente, J., Mateos-Hernández, L., Díez-Delgado, I., et al. (2016). Comparative proteomics identifies host immune system proteins affected by infection with Mycobacterium bovis. PLoS Negl. Trop. Dis. 10:e0004541. doi: 10.1371/journal.pntd.0004541

Mahairas, G. G., Sabo, P. J., Hickey, M. J., Singh, D. C., and Stover, C. K. (1996). Molecular analysis of genetic differences between Mycobacterium bovis BCG and virulent M. bovis. J. Bacteriol. 178, 1274-1282.

Meena, L. S. (2010). Survival mechanisms of pathogenic Mycobacterium tuberculosis H37Rv. FEBS J. 277, 2416-2427. doi: 10.1111/j.1742-4658.2010.07666.x

Meikle, V., Bianco, M. V., Blanco, F. C., Gioffré, A., Garbaccio, S., and Vagnoni, L. (2011). Evaluation of pathogenesis caused in cattle and guinea pig by a Mycobacterium bovis strain isolated from wild boar. BMC Vet. Res. 7:37. doi: 10.1186/1746-6148-7-37

Michel, A. L., Müller, B., and van Helden, P. D. (2010). Mycobacterium bovis at the animal-human interface: a problem, or not? Vet. Microbiol. 140, 371-381. doi: 10.1016/j.vetmic.2009.08.029

Müller, B., Dürr, S., Alonso, S., Hattendorf, J., Laisse, C. J., and Parsons, S. D. (2013). Zoonotic Mycobacterium bovis-induced tuberculosis in humans. Emerg. Infect. Dis. 19, 899-908. doi: 10.3201/eid1906.120543

Naranjo, V., Gortazar, C., Villar, M., and de la Fuente, J. (2007). Comparative genomics and proteomics to study tissue-specific response and function in natural Mycobacterium bovis infections. Anim. Health Res. Rev. 8, 81-88. doi: $10.1017 /$ S1466252307001260

Petriz, B. A., and Franco, O. L. (2014). Application of cutting-edge proteomics technologies for elucidating host-bacteria interactions. Adv. Protein Chem. Struct. Biol. 95, 1-24. doi: 10.1016/B978-0-12-800453-1.00001-4

Price, N. M., Gilman, R. H., Uddin, J., Recavarren, S., and Friedland, J. S. (2003). Unopposed matrix metalloproteinase- 9 expression in human tuberculous granuloma and the role of TNF- $\alpha$-dependent monocyte networks. J. Immunol. 171, 5579-5586. doi: 10.4049/jimmunol.171.10.5579

Rajaram, M. V. S., Ni, B., Dodd, C. E., and Schlesinger, L. S. (2014, December). "Macrophage immunoregulatory pathways in tuberculosis," in Seminars in Immunology Vol. 26, No. 6, ed S. H. E. Kaufmann (Columbus, OH: Academic Press), 471-485. 
Rao, P. K., Singh, C. R., Jagannath, C., and Li, Q. (2009). A systems biology approach to study the phagosomal proteome modulated by mycobacterial infections. Int. J. Clin. Exp. Med. 2:233.

Renwick, A. R., White, P. C. L., and Bengis, R. G. (2007). Bovine tuberculosis in southern African wildlife: a multi-species host-pathogen system. Epidemiol. Infect. 135, 529-540. doi: 10.1017/S0950268806007205

Rohde, K. H., Abramovitch, R. B., and Russell, D. G. (2007). Mycobacterium tuberculosis invasion of macrophages: linking bacterial gene expression to environmental cues. Cell Host Microbe 2, 352-364. doi: 10.1016/j.chom.2007.09.006

Sambarey, A., Prashanthi, K., and Chandra, N. (2013). Mining large-scale response networks reveals 'topmost activities' in Mycobacterium tuberculosis infection. Sci. Rep. 3:2302. doi: 10.1038/srep02302

Saquib, N. M., Jamwal, S., Midha, M. K., Verma, H. N., and Manivel, V. (2015). Quantitative proteomics and lipidomics analysis of endoplasmic reticulum of macrophage infected with Mycobacterium tuberculosis. Int. J. Proteomics 2015:270438. doi: 10.1155/2015/270438

Schmidt, F., and Völker, U. (2011). Proteome analysis of host-pathogen interactions: investigation of pathogen responses to the host cell environment. Proteomics 11, 3203-3211. doi: 10.1002/pmic.201100158

Seki, M., Honda, I., Fujita, I., Yano, I., Yamamoto, S., and Koyama, A. (2009). Whole genome sequence analysis of Mycobacterium bovis bacillus CalmetteGuerin (BCG) Tokyo 172: a comparative study of BCG vaccine substrains. Vaccine 27, 1710-1716. doi: 10.1016/j.vaccine.2009.01.034

Seth, M., Lamont, E. A., Janagama, H. K., Widdel, A., Vulchanova, L., Stabel, J. R., et al. (2009). Biomarker discovery in subclinical mycobacterial infections of cattle. PLoS ONE 4:e5478. doi: 10.1371/journal.pone.0005478

Shah, S., Bohsali, A., Ahlbrand, S. E., Srinivasan, L., Rathinam, V. A. K., Vogel, S. N., et al. (2013). Mycobacterium tuberculosis but not nonvirulent mycobacteria inhibit ifn- $\beta$ and aim2-inflammasome dependent il$1 \beta$ production via their esx-1 secretion system. J. Immunol. 191, 3514-3518. doi: 10.4049/jimmunol.1301331

Sharma, D., Lata, M., Singh, R., Deo, N., Venkatesan, K., and Bisht, D. (2016). Cytosolic proteome profiling of aminoglycosides resistant Mycobacterium tuberculosis clinical isolates using MALDI-TOF/MS. Front. Microbiol. 7:1816. doi: $10.3389 /$ fmicb. 2016.01816

Shui, W., Gilmore, S. A., Sheu, L., Liu, J., Keasling, J. D., and Bertozzi, C. R. (2008). Quantitative proteomic profiling of host-pathogen interactions: the macrophage response to Mycobacterium tuberculosis lipids. J. Proteome Res. 8, 282-289. doi: 10.1021/pr800422e

Singhal, N., Kumar, M., Sharma, D., and Bisht, D. (2016). Comparative protein profiling of intraphagosomal expressed proteins of Mycobacterium bovis BCG. Protein Pept. Lett. 23, 51-54. doi: 10.2174/0929866523666151106123121

van Crevel, R., Ottenhoff, T. H. M., and van der Meer, J. W. M. (2002). Innate immunity to Mycobacterium tuberculosis.
Clin. Microbiol. Rev. 15, 294-309. doi: 10.1128/CMR.15.2.294309.2002

Vázquez, C. L., Bianco, M. V., Blanco, F. C., Forrellad, M. A., Gutierrez, M. G., and Bigi, F. (2016). Mycobacterium bovis requires P27 (LprG) to arrest phagosome maturation and replicate within bovine macrophages. Infect. Immun. 85:e0720-16. doi: 10.1128/IAI.00720-16

Wassermann, R., Gulen, M. F., Sala, C., Perin, S. G., Lou, Y., and Rybniker, J. (2015). Mycobacterium tuberculosis differentially activates cGAS-and inflammasome-dependent intracellular immune responses through ESX-1. Cell Host Microbe 17, 799-810. doi: 10.1016/j.chom.2015.05.003

Weiss, G., and Schaible, U. E. (2015). Macrophage defense mechanisms against intracellular bacteria. Immunol. Rev. 264, 182-203. doi: 10.1111/imr.12266

World Health Organization (2016) Tuberculosis. Fact sheet. Available online at: http://www.who.int/mediacentre/factsheets/fs104/en/

Wu, K., Fang, H., Lyu, L.-D., Lowrie, D. B., Wong, K.-W., and Fan, X.-Y. (2014). A derived network-based interferon-related signature of human macrophages responding to Mycobacterium tuberculosis. Biomed Res. Int. 2014:713071. doi: 10.1155/2014/713071

Yang, M., Wang, Y., Chen, Y., Cheng, Z., Gu, J., and Deng, J. (2015). Succinylome analysis reveals the involvement of lysine succinylation in metabolism in pathogenic Mycobacterium tuberculosis. Mol. Cell. Proteomics 14, 796-811. doi: 10.1074/mcp.M114.045922

Young, B. L., Mlamla, Z., Gqamana, P. P., Smit, S., Roberts, T., Peter, J., et al. (2014). The identification of tuberculosis biomarkers in human urine samples. Eur. Respir. J. 43, 1719-1729. doi: 10.1183/09031936.00175113

Zhang, X., Li, S., Luo, Y., Chen, Y., Cheng, S., and Guo, A. (2013). Mycobacterium bovis and BCG induce different patterns of cytokine and chemokine production in dendritic cells and differentiation patterns in CD4+ T cells. Microbiology 159(Pt 2), 366-379. doi: 10.1099/mic.0.058198-0

Zhou, Y., Shah, S. Z. A., Yang, L., Zhang, Z., Zhou, X., and Zhao, D. (2016). Virulent Mycobacterium bovis Beijing strain activates the NLRP7 inflammasome in THP-1 macrophages. PLoS ONE 11:e0152853. doi: 10.1371/journal.pone.0152853

Conflict of Interest Statement: The authors declare that the research was conducted in the absence of any commercial or financial relationships that could be construed as a potential conflict of interest.

Copyright (c) 2017 Li, Wang, Dong, Hu, Zong, Zhang, Wang, Guo, Zhang, Xiang, Chen and Tan. This is an open-access article distributed under the terms of the Creative Commons Attribution License (CC BY). The use, distribution or reproduction in other forums is permitted, provided the original author(s) or licensor are credited and that the original publication in this journal is cited, in accordance with accepted academic practice. No use, distribution or reproduction is permitted which does not comply with these terms. 